\title{
Tablet for Rectal Suspension Dosage Form
}

National Cancer Institute

\section{Source}

National Cancer Institute. Tablet for Rectal Suspension Dosage Form. NCI Thesaurus.

Code C149982.

Solid, usually single-dose preparation consisting of a tablet, usually uncoated, intended to be dispersed in the specified liquid to obtain a rectal suspension. 